\title{
Leakage of 5'-Guanosine Monophosphate from Candida lipolytica (IFO, 0746) and Its Mutants
}

\author{
Hiroyuki Horitsu, Toshimi Satake, Kiyoshi Ogawa \\ and Mikio TOMOYEDA \\ Department of Agricultural Chemistry, Faculty of Agriculture, \\ Gifu University, Kagamigahara, Gifu 504, Japan
}

Received February 23, 1977

\begin{abstract}
5'-Guanosine monophosphate (5'-GMP) was found to leak from Candida lipolytica (IFO, 0746) and its mutant $Y$ and $\mathrm{Sm}$.

Mutant $\mathrm{Sm}$ obtained from the parent strain by treatment with $\mathrm{N}$-methyl- $\mathrm{N}^{\prime}$-nitro-Nnitrosoguanidine (NTG) and ultraviolet irradiation was found to leak $5^{\prime}$-GMP at 5 times the amount of the parent strain. The properties of mutant $Y$ and $\mathrm{Sm}$ were compared with the parent strain, and differences were present in growth, amount of $5^{\prime}$-GMP leakage and ribonuclease activity.
\end{abstract}

Since leakage of nucleic acid-related substances from yeast was first reported by Challinor and Rose, ${ }^{1}$ Higuchi and Uemura ${ }^{2)}$ also reported that 2'- or 3'-nucleotides leaked from cells of Saccharomyces cerevisiae by shaking in citrate buffer or ethylenediamine tetraacetic acid (EDTA) solution.

In continuation to these reports, screenings of yeasts that leaked nucleotides were carried out by Nakao et $a l .{ }^{3)}$ It was concluded by them that yeasts were divided into four groups according to their ability to leak nucleotides: first, those that leaked 3 '-nucleotides at acid $\mathrm{pH}$; second, those that leaked 5'-nucleotides at alkaline $\mathrm{pH}$; third, those that leaked $5^{\prime}$ nucleotides at both acidic and alkaline pHs; and fourth, those that leaked little nucleotides at acidic or alkaline $\mathrm{pH}$.

There has, however, not yet been a report on Candida yeasts.

Recently, $C$. lipolytica has been recognized as a citric acid producing yeast. ${ }^{4}$ In connection with the report by Higuchi and Uemura ${ }^{2}$ in which some nucleotides were leaked into medium by shaking $S$. cerevisiae cells in citrate buffer, the authors thought that there might be some connection between leakage of nucleotides and citric acid production of $C$. lipolytica. Thus, the authors first tested whether citric acid is produced, and next tested whether nucleotides are leaked by $C$. lipolytica. Then, isolation of mutants that leaked nucleotides much more than the parent strain was carried out by mutagenesis with NTG and by ultraviolet irradiation. Finally, comparisons of properties of the parent strain and mutants were carried out in growth, amount of 5'-GMP leakage and ribonuclease (RNase) activity.

\section{MATERIALS AND METHODS}

Materials. Nucleotides, DEAE-cellulose and Sephadex G-10 were purchased from Nakarai Chemicals Co.

Microorganisms. Candida lipolytica (IFO, 0746) mutant $Y$ was isolated from the parent strain by NTG treatment, and mutant $\mathrm{Sm}$ was isolated from mutant $\mathrm{Y}$ by UV-irradiation as described under Isolation of mutants

Cultural conditions. Medium $\mathrm{A}(100 \mathrm{ml})$ contained $10 \mathrm{~g}$ of D-glucose, $0.5 \mathrm{~g}$ of $\mathrm{NH}_{4} \mathrm{H}_{2} \mathrm{PO}_{4}, 0.05 \mathrm{~g}$ of $\mathrm{KH}_{2} \mathrm{PO}_{4}, 0.05 \mathrm{~g}$ of $\mathrm{MgSO}_{4} \cdot 7 \mathrm{H}_{2} \mathrm{O}, 1 \mathrm{mg}$ of inositol, $50 \mu \mathrm{g}$ each of nicotinamide, riboflavin, pyridoxal and Ca-pantothenate, $10 \mu \mathrm{g}$ of thiamine and $12 \mu \mathrm{g}$ of biotin, adjusted $\mathrm{pH}$ to 6.0 , after sterilization at $120^{\circ} \mathrm{C}$ for $15 \mathrm{~min}$. Agar slant medium $(100 \mathrm{ml})$ contained $10 \mathrm{~g}$ of D-glucose, $0.5 \mathrm{~g}$ each of Polypepton, $\mathrm{NaCl}$ and yeast extract and $2 \mathrm{~g}$ of agar, adjusted $\mathrm{pH}$ to 6.0 , after sterilization at $120^{\circ} \mathrm{C}$ for $15 \mathrm{~min}$. A loopful of agar slant culture was inoculated to $100 \mathrm{ml}$ of medium $\mathrm{A}$ and incubated at $30^{\circ} \mathrm{C}$ for 4 days by shaking $(7 \mathrm{~cm}$ in 
stroke, 140 reciprocation/min). The cells were harvested by centrifugation at $10,000 \mathrm{rpm}$ for $15 \mathrm{~min}$. The cells thus obtained were washed with distilled water until the washings did not show absorbance at $260 \mathrm{~nm}$. The cells ( $10 \mathrm{~g}$ wet weight) were shaken in $50 \mathrm{ml}$ of $0.1 \mathrm{M}$ acetate buffer (pH 6.0) in a $500 \mathrm{ml}$ shaking flask.

Measurement of $260 \mathrm{~nm}$-absorbing substances. The culture fluid was measured on absorbance at $260 \mathrm{~nm}$ with a Shimadzu-UV-200 spectrophotometer.

Isolation of mutants. ${ }^{5)}$ When cell growth of $C$. lipolytica (IFO, 0746) reached the $\log$ phase (cells, $10^{9} /$ $\mathrm{ml}$ ), NTG was added to the culture to give a final concentration of $30 \mu \mathrm{g}$ per $\mathrm{ml}$, and the cultivation was continued for a further $24 \mathrm{hr}$ at $30^{\circ} \mathrm{C}$ with shaking. After treatment with NTG, $0.1 \mathrm{ml}$ of the culture was pipetted up and spreaded over a plate of agar medium $\mathrm{A}$ and incubated at $30^{\circ} \mathrm{C}$ for $24 \mathrm{hr}$. Several colonies appeared on the plate. Among these colonies, a yellow colony which leaked the largest amounts of UV-absorbing substance in the cultivation test was designated as mutant $\mathrm{Y}$ and used for further mutation. Mutant $\mathrm{Y}$ was cultivated in medium $\mathrm{A}$ at $30^{\circ} \mathrm{C}$ for $24 \mathrm{hr}$. The cells were harvested by centrifugation and were suspended into $0.1 \mathrm{M}$ Tris-malate buffer $(\mathrm{pH}$ 6.0) to give a final cell count about $10^{6}$ per ml. Ten milliliters of the cell suspension were poured into a petri fish (diameter, $9 \mathrm{~cm}$ ) and irradiated by a sterilizing lamp (Toshiba, 15W) from a distance of $40 \mathrm{~cm}$ for $1 \mathrm{~min}$. Then, $0.1 \mathrm{ml}$ of the UV-treated suspension was spreaded over a plate of agar medium $\mathrm{A}$ and incubated at $30^{\circ} \mathrm{C}$ for $24 \mathrm{hr}$. Among colonies on the plate, a smooth colony which leaked the largest amounts of UV-absorbing substance in the cultivation test was chosen as mutant Sm.

Identification of leaked substance. For identification of organic acids in broth, to the culture fluid was added one-fifth volume of charcoal to absorb the residual sugar and coloring impurities. After the mixture was filtered, the charcoal portion was washed with water. To the filtrate and washings was added one-fifth volume of Amberlite IR-120 to remove the cathionic impurities. After filtration, to the filtrate was added one-fifth volume of Amberlite $4 \mathrm{~B}$ to absorb the organic acids on the resin. After filtering and washing the resin with water, one-fifth volume of $2 \%$ $\mathrm{NaOH}$ was added to elute the organic acids from the resin. Finally, Amberlite IR-120 was added to convert the sodium salt of organic acid to free acid. Then, the concentrate was kept in a refrigerator for crystallization. The crystals were recrystallized from $\mathrm{MeOH}$, and the melting point of the crystals was determined. But, crystals of organic acid were not obtained in large quantity by this method. To obtain crystals of organic acid in bulk, an experiment was carried out to convert organic acid to derivative of its organic acid in culture fluid. That is, to $200 \mathrm{ml}$ of culture fluid adjusted to $\mathrm{pH} 6.0$ with $1 \mathrm{~N} \mathrm{NaOH}, 0.3 \mathrm{~g}$ of $p$-bromophenacylbromide in $90 \% \mathrm{EtOH}$ was added, and the reaction mixture was refluxed. Then, the crystals formed were separated by filtration from the reaction mixture and dissolved in $4 \mathrm{ml}$ of $99 \% \mathrm{EtOH}$. Crystals were formed by cooling in a refrigerator.

Identification of nucleotide leaked from the yeast. Incubation mixture samples $(5 \mathrm{ml}$ ) were occasionally taken from the shaking mixture and centrifuged at $10,000 \mathrm{rpm}$ for $10 \mathrm{~min}$. The supernatant solution thus obtained was used for measuring the UV-spectrum. Next, the scale up experiment was carried out, that is, $100 \mathrm{ml}$ of supernatant solution were taken from the broth and dialyzed against distilled water. The dialyzed outer solution was concentrated in vacuo at $40^{\circ} \mathrm{C}$, and the concentrated solution was subjected on a Sephadex G-10 column $(2 \times 60 \mathrm{~cm})$ and eluted by distilled water. The flow rate was $5.0 \mathrm{ml}$ per hr, and $5.5 \mathrm{ml}$ each fraction was collected. The UV-absorbing fractions were pooled, adsorbed on a Dowex $1 \times 8 \mathrm{AG}$ column $(0.8 \times 10 \mathrm{~cm})$ equilibrated with $0.005 \mathrm{~N}$ formic acid, and eluted stepwise by $0.005 \mathrm{~N}$-formic acid, $0.02 \mathrm{~N}$-formic acid, $0.17 \mathrm{~N}$-formic acid and $0.17 \mathrm{~N}$ formic acid containing $0.05 \mathrm{~m} \mathrm{Na-formate,} \mathrm{respectively.}$ $\mathrm{Next}$, the eluate with $0.17 \mathrm{~N}$ formic acid- $0.05 \mathrm{M} \mathrm{Na}-$ formate was concentrated and applied to paper chromatography using two kinds of solvents: (1) $\mathrm{MeOH}-$ EtOH-conc. $\mathrm{HCl}-\mathrm{H}_{2} \mathrm{O} \quad(50: 25: 6: 19, \mathrm{v} / \mathrm{v})$ and (2) isoPrOH-conc. $\mathrm{HCl}-\mathrm{H}_{2} \mathrm{O} \quad(65: 16.7: 18.3, \mathrm{v} / \mathrm{v})$. For detection of nucleotides, Super light (Nikko Seiki Works) was used. Thin layer chromatography (TLC) was also conducted on an Avicel Gel plate with the same solvent systems as paper chromatography.

Identification of $5^{\prime}$-nucleotide. To detect whether phosphate bonds of the nucleotide was $5^{\prime}$ - or $3^{\prime}$-linkage, enzymatic cleavage of phosphate bonds of the nucleotide with 5 '-nucleotidase (Sigma) was tested on the nucleotide fraction that had been extracted from the UVabsorbing spot on thin-layer chromatogram with phosphate buffer ( $\mathrm{pH} 9.0)$. Then, inorganic phosphate released was measured by the Fiske-Subbarow's method. ${ }^{6)}$

Intracellular RNase activity. Unless otherwise stated, RNase activity was determined as in the previous paper $^{7}$ except that $0.1 \mathrm{M}$ acetate buffer ( $\mathrm{pH} 6.0$ ) was used as buffer for the enzyme assay.

\section{RESULTS}

\section{Identification of citric acid}

As for organic acids formed by C. lipolytica, Tabuchi et al. ${ }^{4)}$ reported that much citric acid and some isocitric acid were formed. Thus, 
the first experiment was carried out to collect these organic acids from yeast. The result was that only citric acid was identified as the derivative of $p$-bromophenacyl ester (mp, $110^{\circ} \mathrm{C}$.

Relationship of UV-absorbing substance leaked from growing cells or from washed cells with cultivation time

An aliquot of incubation mixture was taken, concentrated and the supernatant solution thus obtained was used for measurement of UV-absorption spectrum to make clear whether the UV-absorbing substance was nucleotide or not. The UV-absorption spectrum showed maximal absorption at about $260 \mathrm{~nm}$ and minimal absorption at about $240 \mathrm{~nm}$.

This means that the UV-absorbing substance is a nucleic acid-related compound. Next, an experiment was carried out using washed cells to confirm this finding. The harvested cells after 4 day-incubation were suspended in $0.1 \mathrm{~m}$ acetate buffer, $\mathrm{pH} 6.0$ and shook. The relationship of the UV-absorbing substance

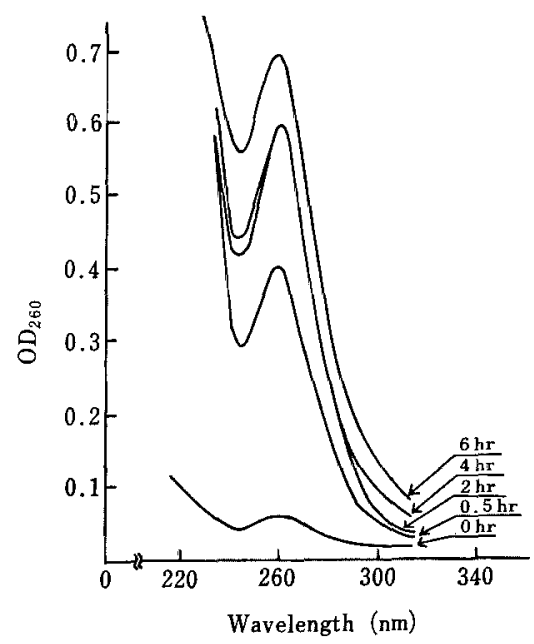

FIG. 1. Leakage of Ultraviolet-absorbing Substance with Incubation Time.

with incubation time is shown in Fig. 1. The amount of UV-absorbing substance increased with incubation time. Changes in $\mathrm{pH}$, growth and $260 \mathrm{~nm}$ UV-absorbing substance with

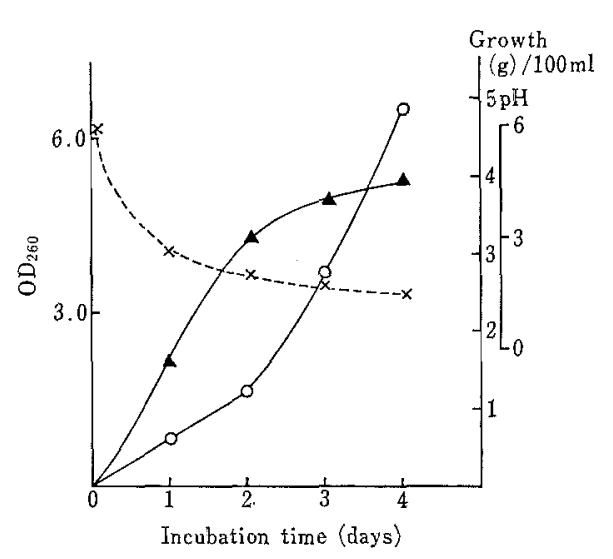

FIG. 2. Changes of $\mathrm{pH}$, Optical Density at $260 \mathrm{~nm}$ and Growth of the Parent Strain. Growth $(\mathrm{O}), \mathrm{pH}$ $(\times)$ and $\mathrm{OD}_{260}(\mathbf{A})$.

incubation time are shown in Fig. 2. The amount of UV-absorbing substance increased with cell growth.

\section{$U V$-absorbing substance}

Result of paper chromatography and TLC with filtrate by washed cells is shown in Table I. Moreover, the following findings clarified that the UV-absorbing substance was 5'-GMP: first, inorganic phosphate was released from the nucleotide by 5 '-nucleotidase; second, the elution pattern of the nucleotide being eluted with $0.17 \mathrm{~N}$-formic acid- $0.05 \mathrm{M}$ Na-formate on Dowex $1 \times 8$ AG column coincided with that of authentic 5'-GMP; and third, ratios of extinction coefficients ( $\mathrm{pH} 7.0)$ of the nucleotide $\left(\varepsilon_{250} / \varepsilon_{260}=1.16, \varepsilon_{280} / \varepsilon_{260}=0.65\right.$ and $\varepsilon_{290} / \varepsilon_{260}=$ 0.30 ) coincided with those of authentic 5'GMP.

\section{Isolation of mutants}

Mutant $\mathrm{Y}$ was isolated from $C$. lipolytica (IFO, 0746) after treatment with NTG, and mutant Sm was obtained from mutant $\mathrm{Y}$ by further UV-irradiation.

\section{Properties of mutant $Y$ and $S m$}

a) Effect of amino acids: Each amino acid of the standard 20 amino acids in concentration of $50 \mathrm{~mm}$ was added to medium $\mathrm{A}$, and the effect of the amino acids on growth was 
Table I. $R f$-Values of Authentic Nucleotides and Ultraviolet Absorbing SUbSTANCE

\begin{tabular}{|c|c|c|c|c|c|}
\hline \multicolumn{3}{|c|}{ Paper chromatography } & \multicolumn{3}{|c|}{ Thin-layer chromatography } \\
\hline Solvent system & $\mathrm{A}(R f)$ & $\mathrm{B}(R f)$ & Solvent system & $\mathrm{A}(R f)$ & B $(R f)$ \\
\hline $5^{\prime}-\mathrm{AMP}$ & $0.40, \mathrm{DV}$ & $0.38, \mathrm{DV}$ & 5'-AMP & $0.38, \mathrm{DV}$ & $0.00, \mathrm{DV}$ \\
\hline $5^{\prime}-\mathrm{CMP}$ & $0.00, \mathrm{DV}$ & $0.45, \mathrm{DV}$ & $5^{\prime}-\mathrm{CMP}$ & $0.45, \mathrm{DV}$ & $0.49, \mathrm{DV}$ \\
\hline 5'-GMP & $0.32, \mathrm{~W}$ & $0.30, \mathrm{~W}$ & $5^{\prime}-\mathrm{GMP}$ & $0.30, \mathrm{~W}$ & $0.28, \mathrm{~W}$ \\
\hline \multirow{2}{*}{ 5'-UMP } & $0.61, \mathrm{DV}$ & $0.67, \mathrm{DV}$ & $2^{\prime}\left(3^{\prime}\right)-\mathrm{GMP}$ & $0.39, \mathrm{~W}$ & $0.37, \mathrm{w}$ \\
\hline & & & 5'-UMP & $0.67, \mathrm{DV}$ & $0.00, \mathrm{DV}$ \\
\hline $\begin{array}{l}\text { UV-absorbing } \\
\text { substance }\end{array}$ & $0.32, \mathrm{~W}$ & $0.30, W$ & $\begin{array}{l}\text { UV-absorbing } \\
\text { substance }\end{array}$ & $0.30, \mathrm{~W}$ & $0.28, \mathrm{~W}$ \\
\hline
\end{tabular}

Note: A system: $\mathrm{MeOH}-\mathrm{EtOH}-$ conc. $\mathrm{HCl}-\mathrm{H}_{2} \mathrm{O}(50: 25: 6: 19, \mathrm{v} / \mathrm{v})$.

B system: iso-PrOH-conc. $\mathrm{HCl}-\mathrm{H}_{2} \mathrm{O}(65: 16.7: 18.3, \mathrm{v} / \mathrm{v})$.

$\mathrm{W}$, white color by UV-lamp detector.

DV, deep violet color by UV-lamp detector.

checked. Among these amino acids, serine, aspartic acid, methionine and arginine produced stimulative effects on growth of mutant $\mathrm{Y}$ and $\mathrm{Sm}$ as well as the parent strain, whereas cysteine inhibited growth at the initial stage of the two mutants. These effects, however, decreased with a lapse of incubation time. b) Effect of vitamins: The effect of thiamine and other vitamins was checked. As expected, mutant $\mathrm{Y}$ and $\mathrm{Sm}$ as well as the parent strain required thiamine for growth. As Rose ${ }^{8)}$ reported that the permeability of $C$. albicans increased by the absence of biotin in medium, the effect of biotin on the parent strain and mutant $\mathrm{Y}$ and $\mathrm{Sm}$ was tested. There was no effect with biotin on permeability of mutant

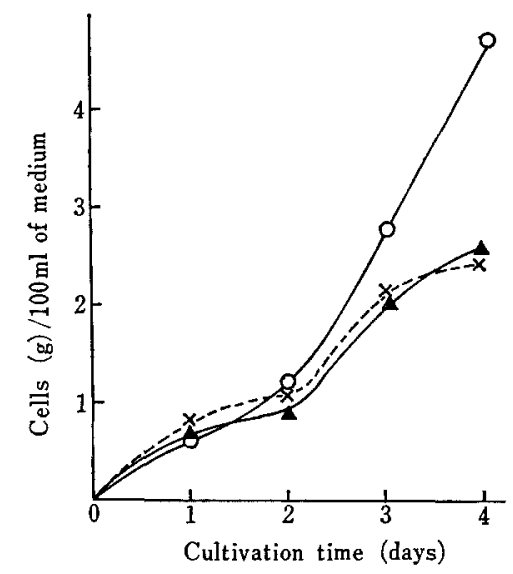

FIG. 3. Growth with Cultivation Time.

Parent strain (O), mutant $\mathrm{Y}(\boldsymbol{\Lambda})$ and mutant $\operatorname{Sm}(\mathrm{x})$.
$\mathrm{Y}$ and $\mathrm{Sm}$ as well as the parent strain. c) About growth: A comparison of the growth curve of the parent strain with mutant $\mathrm{Y}$ and Sm is shown in Fig. 3.

A similar growth was found in all strains up to 2 days but after 2 days, the growth of mutant $\mathrm{Y}$ and $\mathrm{Sm}$ decreased compared with the parent strain. d) Effect of glucose: A comparison of glucose consumption in the parent strain with mutant $\mathrm{Y}$ and Sm is shown in Fig. 4. Mutant $\mathrm{Sm}$ showed a similar pattern to the parent strain, but mutant $Y$ showed a different pattern compared with the two other strains. e) Leakage of UV-absorbing substance: A comparison of the amount of UV-absorbing substance from the parent strain with mutant $Y$ and $\mathrm{Sm}$ is shown in Fig. 5. There was about

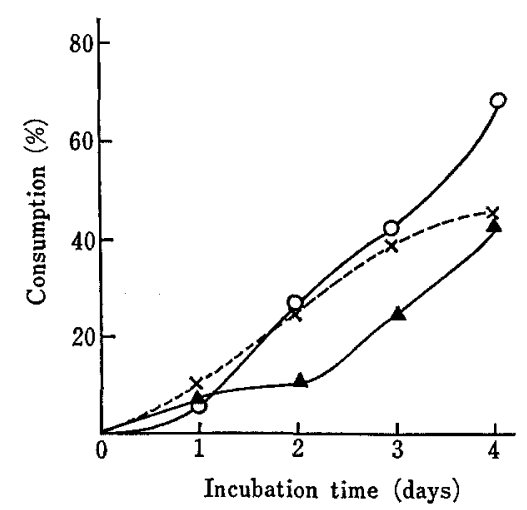

Fig. 4. Consumption of Glucose with Incubation Time.

Parent strain $(O)$, mutant $Y(\Lambda)$ and mutant $\operatorname{Sm}(\times)$. 


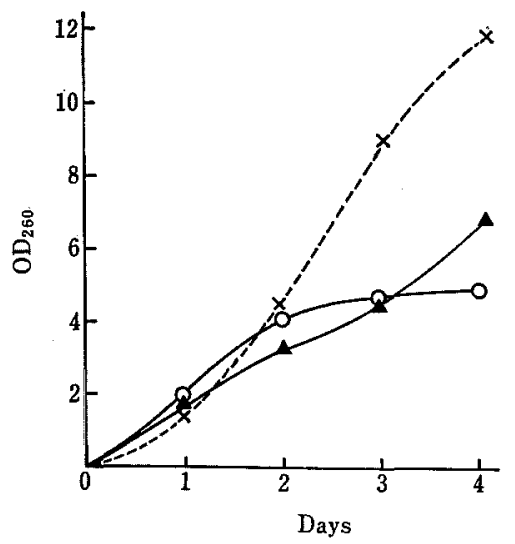

FIG. 5. Leakage of Ultraviolet-Absorbing Substance with Incubation Time.

Parent strain $(\mathrm{O})$, mutant $\mathrm{Y}(\boldsymbol{\Delta})$ and mutant $\mathrm{Sm}(\times)$.

5 times more UV-absorbing substance by mutant Sm than by the parent strain. f) About intracellular RNase: Cells $(15 \mathrm{~g}$ wet weight) from the parent strain and mutant $Y$ or Sm, were disrupted by a Braun cell homogenizer, and the respective cell-free extracts were obtained after centrifugation. After dialysis against distilled water overnight, the RNase activities from the three preparations were compared. Mutant $\mathrm{Y}$ and $\mathrm{Sm}$ both showed about one-ninth the RNase activity compared with the parent strain. Comparison of some properties, cell growth, consumption of glucose, RNase activity and UV-absorbing substance of the parent strain with mutant $Y$ and $\mathrm{Sm}$ is shown in Table II.

Table II. Comparisons of Properties of the Parent Strain With Mutant Y and Sm

\begin{tabular}{lcrcr}
\hline Strain & $\begin{array}{c}\text { Cells (g)/ } \\
100 \mathrm{ml} \\
\text { of culture }\end{array}$ & $\begin{array}{c}\text { RNase } \\
\text { (Relative } \\
\text { activity) }\end{array}$ & $\begin{array}{c}\text { Consumption } \\
\text { of glucose }(\%)\end{array}$ & $\begin{array}{c}\mathrm{OD}_{260} \\
\text { g.D.W }\end{array}$ \\
\hline Parent & 4.08 & 100.0 & 65.2 & 1.30 \\
$\mathrm{Y}$ & 2.19 & 11.6 & 48.2 & 3.11 \\
$\mathrm{Sm}$ & 1.80 & 11.9 & 37.8 & 6.44 \\
\hline
\end{tabular}

\section{DISCUSSION}

As described in the introduction for leakage of nucleotides from yeasts, Higuchi and Uemura $^{2)}$ reported that $3^{\prime}$ - or $2^{\prime}$-nucleotides were leaked from washed cells of $S$. cerevisiae by shaking in $0.1 \mathrm{M}$ acetate buffer ( $\mathrm{pH}$ 6.0). Nakao et al. ${ }^{3)}$ later reported in detail that the yeasts of Rhodotorula, Schizosaccharomyces and Saccharomyces leaked 5'-nucleotides. They concluded that $3^{\prime}$-nucleotides were leaked at acid $\mathrm{pH}$, but $5^{\prime}$-nucleotides were ordinarly leaked at alkaline $\mathrm{pH}$. However, in Rhodotorula pakkida, 5'-nucleotides leaked both at acidic and alkaline pHs. In our experiments with C. lipolytica, only 5'-GMP leaked at acidic $\mathrm{pH}$. It means that this yeast belongs to another type. Moreover, from the finding that degradative type of intracellular RNase of this yeast belongs to 3 '-former, 5'-GMP must be produced by another enzyme than intracellular RNase, but on this point, it is necessary to examine the problem further in more detail.

As to the relationship between nucleotides leakage and mutation, Tsukada and Sugimori ${ }^{9}$ ) have already reported that a mutant obtained from $Z$ ygosaccharomyces soja by cycloheximide treatment leaked 5'-nucleotides in larger amounts than the parent strain. In addition, it has been reported by Ikeno et al., ${ }^{10)}$ that a mutant obtained from $C$. lipolytica by NTG treatment leaked citric acid in larger amounts than the parent strain. By combining the above procedures, we tried to get mutants with the capacity to leak 5'-GMP by treatment similar to the above methods and got mutant $Y$ which leaked 5'-GMP 2.5 times more than the parent strain. Next, we obtained another mutant which leaked 5'-GMP at 5 times more than the parent strain by irradiating mutant $Y$ with UV lamp. These results suggest that by mutation with UV-irradiation or NTG, some changes may occur in the structure of the cell membrane, and 5'-GMP was leaked in larger amounts.

\section{REFERENCES}

1) S. W. Challinor and A. H. Rose, Nature, 174, 877 (1954).

2) M. Higuchi and T. Uemura, Nippon Nôgeikagaku Kaishi, 33, 304, 821, 826 (1963).

3) Y. Nakao, I. Nogami and K. Ogata, Agric. Biol. 
Chem., 27, 507 (1963).

4) T. Tabuchi, Y. Tanaka and M. Abe, Nippon Nôgeikagaku Kaishi, 43, 154 (1969); 44, 493, 499 (1970).

5) E. A. Adelberg, M. Mandel and G. C. C. Chen, Biochim. Biophys. Res. Commun., 18, 788 (1965).

6) C. H. Fiske and Y. Subbarow, J. Biol. Chem., 66, 375 (1925).
7) H. Horitsu, K. Ogawa and M. Tomoyeda, Res. Bull. Fac. Agr. Gifu Univ., 36, 147 (1974).

8) R. A. Rose, J. Gen. Microbiol., 31, 151 (1963).

9) Y. Tsukada and T. Sugimori, Agric. Biol. Chem., 28, 471 (1964).

10) Y. Ikeno, M. Masuda, K. Tano, I. Oomori and N. Takahashi, J. Ferment. Technol., 53, 752 (1975). 